\title{
DOES POST PARTUM PELVIC FLOOR EXERCISES REDUCE ANAL AND URINARY INCONTINENCE?
}

\section{Mohamed El-Negeri", Mohamed Eltotongy ${ }^{*}$,Maged Elshamy ${ }^{*}$ Abd A. Elrefaei*, Yasser Abdel Dayem ", waleed Omar ${ }^{* * *}$, Waleed Thabet ${ }^{* *}$}

Department of Obstetrics and Gynecology*, Anorectal Unit Department of General Surgery**

Mansoura University Hospitals, Faculty of Medicine, Mansoura University

\section{ABSTRACT}

Post partum anal and urinary incontinence are potentially debilitating conditions, the incidence of which has been grossly under appreciated mainly due to the reluctance of women to seek medical attention for this sensitive problem. Recent epidemiologic studies have highlighted the fact that anal and urinary incontinence after childbirth is not as rare as has been assumed.

Objective: To assess the effect of pelvic floor exercises after vaginal delivery on pelvic floor characteristics using clinical assessment and perineal and endoanal ultrasonography in nulliparous women.

Design : Prospective cohort study.

Methods: 355 primigravid women were enrolled in the study between January 2004 to December 2007 who were attending antenatal care of obstetrics \& gynecologic department, Mansoura University from whom 205 women who delivered vaginally at the emergency unit of the same department completed the study. Those nulliparous women were examined during pregnancy, 6 weeks and 12 months after vaginal delivery; the method used included questionnaire, clinical examination, perineal sonography and endoanal ultrasonography for assessment of the integrity of pelvic floor muscles. After 1 he $2^{\text {nd }}$ examination the women were assigned in alternating manner to either 12 seessions of pelvic floor exercise $(n=102)$ or no training $(2=103)$ and the two groups were compared in the $3^{\text {rd }}$ examimation.

Results: There was a significant decrease in the incidence of urinary and anal incontinence in the group who underwent pelvic floor exercise $62 \%$ vs $6 \%$ in UI \& $70 \%$ vs $0 \%$ in anal incontinence respectively $(\mathrm{p}=0.002)$.

Conclusion: Pelvic floor exercises starting 6 weeks postpartum significantly reduced the incidence of stress urinary incontinence and anal incontinence.

\section{INTRODUCTION}

Trauma during vaginal delivery might result in a variety of pelvic floor complaints (stress urinary incontinence and fecal incontinence are the most frequent and long standing). Stress urinary incontinence is observed in 20-34\% of women after vaginal delivery, $(3 \%$ with daily or more frequent leakage $\left.{ }^{(1)}\right)$. Stress urinary incontinence persist post partum in $29 \%$ of women in whom it appeared during pregnancy and present denovo in $16 \%$ of pregnancy continent women ${ }^{(2)}$. Fecal incontinence is seen in
$4-7 \%$ of primiparous ${ }^{(3)}$ women and transanal ultrasonography demonstrate occult anal sphincter lessions in $35 \%$ of primiparas ${ }^{(4)}$.

Pelvic floor excrcises education, electrical stimulation and biofecd back has gained acceptance during the past 15 years and might cure $(30-50 \%)$ or decrease $(60-90 \%)$ the incidence if stress urinary incontinence ${ }^{(5)}$. The efficacy of these different techniques used separately is controversial because the treatment protocol and the duration of rchabilitation period differ between the studies ${ }^{(6)}$. So, the answer of the question is still unclear; and we 
must try to define the effectiveness of pelvic floor exercises 6 weeks postpartum and for a longer period in the integrity of pelvic floor muscle, based on patient self report and document the answers with endoanal and perineal sonography.

\section{MATERIALS \& METHODS}

All participants were enrolled from the outpatient and inpatient Antenatal Care \& Clinic in the Department of Obs \& Gyn Mansoura University. All the assigned patients were primiparous who had a singleton, delivery vertex, full term (> 37 weeks), who should complete their antenatal care and delivery at our department. In total, 355 were enrolled and 205 completed the study. all participants signed an informed consent to enrollment. The cnrollment period was 3 years. We excluded women with pregnancy complications or delivery complications (multiple vaginal laceration or $3^{\text {rd }}$ degrec perineal tears or prolonged $2^{\text {nd }}$ stage of opcrative deliverics (vacuum or forceps). Careful history was taken with stress on urinary infection or incontinence and fecal incontinence.

All participant were subjected to conventional clinical examination to evaluate the strength of pelvic flnor muscular contraction using a subjective scale U-5 and then perineo-sonography was done to assess the bladder neck position at rest and during valsulva maneuver and pelvic floor contraction in supine and standing positions with bladder containing 200-300 ml. The bladder volume was estimated: transverse diameter $\mathrm{x}$ horizontal diameter $\mathrm{x}$ saggital diameter $\mathrm{x}$ $0.7^{(7)}$. A convex linear transducer $3.5 \mathrm{MhZ}$ was placed on the vulva in a saggital orientation to provide complete view of bladder base and neck, urethra and pubic symphysis.

We performed initial examination antepartum at 37 weeks gestation and $2^{\text {nd }}$ assessment $6^{\text {th }}$ week postpartum, then each woman was then assigned to one of the two groups. a control group (103) patients didn't receive andy education until the third examination conducted $12^{\text {th }}$ month post partum.

Another group (102), where the patients received pelvic floor cducation starting from the $6^{\text {th }}$ weck postpartum and repeated 2 sessions weekly until the time of 3 rd assessment $12^{\text {th }}$ month postpartum. Pelvic floor exercise was done based on kegel exercise that involve contracting the pelvic floor up and in lowards the back holding for several seconds and releasing. this was done 5 times a day, twice per weck regularly till the $3^{\text {rd }}$ examination.

\section{Statistics}

We used students paired two-tailed $t$ test for comparison of same patient measures and student unpaired two tailed $t$-test for comparison. The same patients Dichotomous variables were compared using two sided Fisher's exact test. Either group changes for dichotomous variables were evaluated by continuous Mcnrmar's test and within group changes for continuous variables were evaluated by student paired two-tailed t-test An alpha error of <.05 wits used.

\section{RESULTS}

(Table I) presents the descriptive characteristics of the study population. The mean (SD) for age, body weight and height present no statistical difference in both groups. Also, the duration of $2^{\text {nd }}$ stage and the fetal birth weight presented no statistical difference.

(Table II) presents the effect of pelvic floor exercises on tress urinary incontinence complants. The women who underwent education expersenced significant reduction in the incidence of stress unnary incontunence compared with women who did not perform this practice. Also, incidence of tecal incontinence was significantly different in both groups.

(Table III) shows that the incidence of womens who recovered normal pelvic floor contractuon ats measured by digital exam of pelvic floor muscles 
strength and perineal sonography was statistically different in both groups.

When compared 12 months post partum the two groups had bladder neck postitions in the upright positions and similar bladder neck mobility during stress when supine.

Table (I): Descriptive characteristics of women and events during delivery.

\begin{tabular}{|l|c|c|}
\hline \multicolumn{1}{|c|}{ Characteristics } & $\begin{array}{c}\text { Control group } \\
(\mathbf{n = 1 0 3})\end{array}$ & $\begin{array}{c}\text { Educated group } \\
(\mathbf{n}=\mathbf{1 0 2})\end{array}$ \\
\hline Age $:$ (years) & 13 & 14 \\
$<20$ & 54 & 52 \\
$20-24$ & 36 & 36 \\
$24-29$ & $22(20.48 \%)$ & $19(18.72 \%)$ \\
\hline Weight $(\mathbf{K g m}$ ) & $25(23.81 \%)$ & $33(32.51 \%)$ \\
$<54$ & $28(27.14 \%)$ & $29(28.57 \%)$ \\
$54-61$ & $28(28.57 \%)$ & $21(20.20 \%)$ \\
$62-70$ & & $18(17 \%)$ \\
$>7$ & $19(18.10)$ & $30(29.27)$ \\
\hline Height (cm) & $13(30.95)$ & $30(30.73)$ \\
$<160$ & $25(24.24)$ & $24(22.44)$ \\
\hline $160-161$ & $28(26.71)$ & 3374 \\
\hline $166-170$ & 3340 & Median $32 \pm 1.2$ \\
\hline 170 & Median $28 \pm 3.5$ & \\
\hline Birth weight (gm) Median & & \\
\hline duration of 2nd stage of labour in minutes & & \\
\hline
\end{tabular}

Table (II): Incidence of stress urinary incontinence and fecal incontinence.

\begin{tabular}{|l|c|c|c|c|}
\hline & $\mathbf{1}^{\text {st }}$ exam & $2^{\text {nd }}$ exam & $3^{\text {rd }}$ exam & Subject cured \\
\hline Stress urinary incontinence & & & & \\
Control gp (\%)* & 0 & $30(29.12 \%)$ & $28(14 \%)$ & $2(6 \%)$ \\
Educated gp (\%)** & 0 & $32(31.4 \%)$ & $12(12 \%)$ & $20(26.5 \%)$ \\
p Fisher's exact test & & 0.1 & 0.8 & \\
Fecal incontinence & & & & \\
Control gp (\%)* & 0 & $5(10 \%)$ & $5(10 \%)$ & 0 \\
Educated gp (\%)** & 0 & $7(8 \%)$ & $2(28 \%)$ & $5(71 \%)$ \\
p Fisher's exact test & & 0.9 & 0.9 & \\
\hline
\end{tabular}

* $\mathrm{n}=103$

$* * n=102$

Mcnmar's test $\mathrm{p}=1$

Mcnrmar's test $p=.002$ 
Table (III): Incidence of week pelvic floor.

\begin{tabular}{|l|c|c|c|c|}
\hline & $\mathbf{1}^{\text {st }}$ exam & $2^{\text {nd }}$ exam & $3^{\text {rd }}$ exam & $\begin{array}{c}\text { Subject recovering } \\
\text { normal pelvic floor }\end{array}$ \\
\hline Control gp (\%)* & 0 & $50(88 \%)$ & $36(22 \%)$ & $14(28 \%)$ \\
Educated gp (\%) $* *$ & 0 & $50(98 \%)$ & $8(16 \%)$ & $42(84 \%)$ \\
p Fisher's exact test**** & 0.7 & 0.7 & & \\
\hline
\end{tabular}

* $\mathrm{n}=103$

$* * \mathrm{n}=102$

$* * *$ Mcnrmar's test $\mathrm{p}=1$

$* * * *$ Mcnrmar's test $p=.002$

Table (IV): Perineo-sonography after 12 months in comparison with previous assessment.

\begin{tabular}{|l|c|c|c|c|}
\hline & $\mathbf{1}^{\text {st }}$ exam & $2^{\text {nd }}$ exam & $\mathbf{3}^{\text {rd }}$ exam & $\begin{array}{c}\text { Subject recovering } \\
\text { normal pelvic floor }\end{array}$ \\
\hline Bladder neck position in standing & & & & \\
Control gp (\%) & $27 \pm 6$ & $25 \pm 5$ & $28 \pm 5$ & 0.1 \\
Educated gp (\%) & $36 \pm 5$ & $24 \pm 6$ & $28 \pm 4$ & 0.3 \\
p Fisher's cxact test & 0.5 & 0.7 & 0.9 & \\
Bladder neck position in supine & & & & 0.2 \\
Control gp (\%) & $11 \pm 4$ & $13 \pm 4$ & $15 \pm 6$ & 0.6 \\
Educated gp (\%) & $11 \pm 5$ & $14 \pm 6$ & $14 \pm 5$ & 0.4 \\
p Fisher's exact test & 0.5 & 0.4 & 0.4 \\
\hline
\end{tabular}

Data are expressed as mean \pm standard deviation

Students paired $t$ test within groups changes

Student's unpaired $t$ test

Table (V): Difference in patient expressions.

\begin{tabular}{|l|c|c|c|}
\hline & $\begin{array}{c}\text { Excellent } \\
\text { improvement }\end{array}$ & $\begin{array}{c}\text { Moderate } \\
\text { improvement }\end{array}$ & No improvement \\
\hline Control groups $\mathrm{n}=103$ & 0 & $10(9 \%)$ & $93(91 \%)$ \\
Educated group $\mathrm{n}=102$ & $71(70 \%)$ & $21(20 \%)$ & $9(10 \%)$ \\
\hline
\end{tabular}

\section{DISCUSSION}

With a declining obstetric morbidity and mortality in the developed world and the changing roles of women in society, morc attention has focussed on improving the quality of life following childbirth.
One area of increasing controversy has been the potential adverse influence of obstetric factors on the incidence of pelvic floor dysfunction, including prolapsc, urinary incontinence (UI), lecal incontinence (FI) and sexual dysfunction. The potential reduction of pelvic floor dysfunction assciated with cesarean section was suggested by 
Sultan et al ${ }^{(8)}$ in 1996 when his group found that the incidence of anal incontinence was apparently greater among women delivered vaginally than those delivered by CS. Since the publication of this paper, a large literature has examined the effect of spontaneous vaginl birth (SVB), instrumental delivery (ID), and CS on the occurrence of pelvic floor dysfunction. With the generation of more data demonstrating adverse effects of vaginal birth (VB) on pelvic floor function, it had been suggested that performing CS might be efficacious in reducing pelvic floor damage and symptoms ${ }^{(9,10)}$. There is evidence from physiologic and ultrasound studies showing apparently adverse effects of VB on aspects of pelvic floor functioning, including decreased pelvic organ support ${ }^{(11)}$, damage to the levator ani muscles ${ }^{(12)}$, and changes in pudendal nerve function ${ }^{(12)}$. However the clinical significance or importance of these changes to women is aggressively debated.

Pelvic floor education using exercise, electrical stimulation and biofeedback has gained acceptance during the past 15 years and might decrease the incidence of stress urinary and fecal incontinence.

The efficacy of these techniques in the prevention of stress urinary incontinence is uncertain ${ }^{(13)}$. Therefore, we used together with subjective symptoms of patients, ultrasound (perineal and endoanal) was used for assessment and follow up the effect of pelvic excerise, post partum in the pelvic floor functions. An education period of 12 months (two sessions/wk) to compare pelvic floor characteristics of women receiving pelvic floor education with women who did not receive education. The results described in the few studies with control groups are varied and conflicting. Norton and Baker ${ }^{(14)}$ studied primiparas assigned to pelvic floor exercise, and control groups and found that those groups 6 months postpartum imroved to a common endopint when their pelvic floor muscle functions were assessed by perineometry and digitally. In a small cohort of women with persisting stress urinary incontinence 3 months postpartum,
Dumoulin et al (15) found that pelvic floor electostimulation results in a significant increase in vaginal pressure and a significant reduction in stress urinary incontinence, but that study lacked control subjects. In a prospective comparison of 99 matched pairs of mothers divided into a trained group and a control group, Morkved and Bo ${ }^{(16)}$ found that pelvic floor muscle exercises performed for 8 weeks starting 8 weeks postpartum significantly reduced urinary incontinence and significantly increased pelvic floor muscel strength in the trained grou. Wilson and Herbison (17) performed a similar study that compared 1 year postpartum 113 women trained and monitored regularly by a physiotherapist with 117 women using standard postnatal pelvic floor exercises. They found that the prevalence of incontinence was significantly lower in the physiotherapist-trained group than in the other, with no significant differences in perineometry measurements.

We found similar effects of pelvic floor rehabilitation on the incidence of stress urinary incontinence, which was reduced by $62.5 \%$ in women receiving pelvic floor education and by only $2 \%$ in the control group $(P=.03)$.

Pelvic floor education with biofeedback techniques has demonstrated benefit in $89 \%$ of women with residual fecal incontinence after sphincteroplasty ${ }^{(18)}$ and in $67 \%$ of women with fecal incontinence after vaginal delivery ${ }^{(19)}$. Likewise, electrostimulation has been used successfully in $46 \%$ of women with fecal incontinence, particularly those with moderate fecal incontinence ${ }^{(20)}$. In our study, $6 \%$ of women demonstrated moderate fecal incontinence that was unchanged in the control group but $70 \%$ improvement occurred after pelvic floor exercise.

A review of questionnaires completed by study participants showed that $70 \%$ of the pelvic flooreducated women described themselves as feeling that 
they had greatly improved pelvic floor function control, whereas $20 \%$ and $10 \%$ assessed themselves as moderately improved and unimproved, respectively.

In conclusion, we found that postpartum education for pelvic floor exercise is a cheap simple, rapidly accepted method with good complaiance, for improving the post partum pelvic floor dysfunction, reducing the incidence of stress urinary and fecal incontinence and reducing their surgical corrections.

\section{REFERENCES}

1. Wilson PD, Herbison RM, Herbison GP. Obstetric practice and the prevalence of urinary incontinence three months after delivery. Br J Obstet Gynaecol 1996; 103: 154-161.

2. MacArthur C, Lewis M, Knox EG. Health after childbirth. Br J Obstet Gynaecol 1991; 98: 1193-1195.

3. Meyer S, Schrcyer $\Lambda$, De Grandi P, Hohlfeld P. The effects of birt on urinary continence mechanisms and other pclvic-floor characteristics. Obstet Gynecol 1998; 92: 613-918.

4. Sultan AH, Kamm MA, Hudson CN, Thomas JM, Bartram CI. Anal sphincter disruption during vaginal delivery. N Engl J Med 1993; 329: 1905-1911.

5. Yamanishi T, Yasuda K. Electrical stimulation for stress incontinence. Int Urogynecol J Pelvic Floor Disord 1998; 9: 281-290.

6. Miller K, Richardson A, Siegel SW, Karram M, Blackwood NB, Sand PK. Pelvic floor electrical stimulation for genuine stress incontinence: Who will benefit and when?'Int Urogynecol J Pelvic Floor Disord 1998; 9: 265-270.

7. Rosenzweig BA. Radiologic studies of the lower urinary tract. In: Walters MD, Karram MM, eds. Clinical urogynecology. Boston: Mosby, 1993: 132-147.

8. Sultan AH, Monga AK, Stanton SL. The pelvic floor sequelae of childbirth. Br J Hosp Mcd. 1996; 55: 575-579.

9. O'Boyle AL, Davis GD, Calhoun BC. Infórméd consent and birth: protecting the pelvic floor and ourselves. Am J Obstet Gynecol. 2002 187: 981-983.

10. Sultan AH, Stanton SL. Preserving the pelvic lloor and perineum during childbirth- elective cacsarean? Br J Obstet Gynaecol. 1996; 103: 731-734.

11. Dietz HP, Bennett MJ. The effect of childbirth on pelvic organ mobility. Obstet Gynecol. 2003; 1(12: 223-228.

12. Delancey JOL, Kearney R, Queena C, Speights S, Binno $S$. The appearance of levator ani muscle abnormalities in magnetic resonance images after vaginal delivery. Obstet Gynecol. 2003; 101:'46-53;

13. Sultan AH, Kamm MA, Hudson CN. 'Pudéndal nerve damage during labour: prospective study before and after childbirth. Br J Obstet Gynaecol. 1994; 101: 22-28.

14. Mac Arthur C, Bick DE, Keighley MRB. Faecal incontinence after childbirth. Br J Obstet Gynaecol 1997; 104: 46-50.

15. Dumoulin C, Seaborne DE, Quirion-De Girardi C, Sullivan SJ. Pelvic floor rehabilitation, part 2: Pclvic floor reeducation with interferential currents and exercise in the treatment of genuine stress incontinence in post-partum women, a cohort study. Phys Ther 1995; 75: 1075-1081.

16. Morkved S, Bo K. The effect of postpartum pelvic floor muscel exercise in te prevention and treatment of urinary incontinence. Int Urogynecol J 1997; 8: 217-111.

17. Wilson PD, erbison GP. A randomised controlled trial of pelvic floor muscel exercises to treat postnatal urinary incontinence. Int Urogynecol J Pelvic Floor Disord 1998; 9: 257-264.

18. Jensen LL, Lowry AC. Biofeedback improves functional outcome after sphincteroplasty. Dis Colon Rectum 1997; 40: 197-2000.

19. Rieger NA, Wattchow DA, Sarre RG, Cooper SJ, Rich CA, Saccone GT, et al. Prospective trial of pelvic floor retraining in patients with fecal incontinence. Dis Colon Rectum 1997; 40: $821-6$.

20. Leroi AM, Dorival MP, Lecouturier MF, Saiter C, Welter ML, Touchais JY, ct al. Pudendal neuropathy and severity of incontinence but not presence of an anal sphincter defect may determine the response to biofeedback therap in fecal incotitinence. Dis Colon Rectum 1999; 42: 762-769...... : 